\title{
Development of Multi-Functional Hybrid Carbon-Based Nano-Reinforced Epoxy Adhesives
}

\author{
Konstantina Zafeiropoulou', Christina Kostagiannakopoulou1, Marita Georgopoulou', \\ Christina Vogiantzi ${ }^{1}$, Theodoros Loutas ${ }^{1}$, Stavros Tsantzalis ${ }^{1}$, George Sotiriadis ${ }^{1}$, \\ Vassilis Kostopoulos ${ }^{1,2^{*}}$
}

${ }^{1}$ Department of Mechanical Engineering \& Aeronautics, University Campus Patras, Rio Achaia, Greece ${ }^{2}$ Foundation of Research and Technology, Institute of Chemical Engineering Sciences (FORTH/ICE-HT), Rio Achaia, Greece Email: ^kostop@upatras.gr

How to cite this paper: Zafeiropoulou, K., Kostagiannakopoulou, C., Georgopoulou, M., Vogiantzi, C., Loutas, T., Tsantzalis, S., Sotiriadis, G. and Kostopoulos, V. (2021) Development of Multi-Functional Hybrid Carbon-Based Nano-Reinforced Epoxy Adhesives. World Journal of Mechanics, 11, 258274

https://doi.org/10.4236/wjm.2021.1112017

Received: November 11, 2021

Accepted: December 27, 2021

Published: December 30, 2021

Copyright $\odot 2021$ by author(s) and Scientific Research Publishing Inc. This work is licensed under the Creative Commons Attribution International License (CC BY 4.0).

http://creativecommons.org/licenses/by/4.0/

\begin{abstract}
In an effort to expand the insulating behavior of adhesives, incorporated nano-sized fillers, such as multi-walled carbon nanotubes (MWCNTs) and graphene nanoplatelets (GNPs), are usually selected. Including both MWCNTs and GNPs into polymers is assumed to have complementary influence (synergy), providing a new research area. Nevertheless, limited studies have been carried out towards this hybrid direction, as it is challenging to achieve a uniform distribution of both fillers into the polymer matrix. In this work, the addition of MWCNTs and GNPs into the epoxy adhesives has been studied to increase their thermal and electrical conductivity without diminishing their mechanical properties. Three types of nano-reinforced adhesives were developed by using: 1) 2\%wt. MWCNTs, 2) $8 \%$ wt. GNPs and 3) $1 \%$ wt. MWCNTs and $8 \%$ wt. GNPs. The production of nano-reinforced adhesives was achieved by using a three-roll milling technique, while during the experimental characterization single lap shear tests, thermal and electrical conductivity measurements were performed. According to the results, the introduction of nano-particles caused significant increases in electrical and thermal conductivity. MWCNTs in content of $2 \% w t$. showed the highest improvement in the electrical conductivity ( 9 orders of magnitude), while GNPs in content of $8 \%$ wt. recorded the highest increase $(207 \%)$ in the thermal conductivity of nano-reinforced adhesives. Finally, it was observed that the hybrid system successfully contributed to the development of a multi-functional epoxy adhesive with improved thermal and electrical properties without significantly compromising its mechanical properties.
\end{abstract}




\section{Keywords}

Graphene Nanoplatelets, Multi-Walled Carbon Nanotubes, Adhesives, Hybrid Nanocomposites

\section{Introduction}

The design of an advanced structure has to meet certain requirements, such as efficiency, safety and reliability, which affect the complexity of the structure and the materials used in its construction. The materials used in these structures require a combination of high stiffness, strength, fracture toughness and corrosion resistance. Especially, aerospace materials must be also able to withstand the aerodynamic and structural loads, must be damage tolerant and provide durability over the aircraft operational life, easy to manufacture, and lightweight [1].

Hybrid structures are one promising solution to fulfill these requirements. Towards that, suitable joining techniques, such as adhesive bonding, are required. The two basic joining methods are adhesive bonding and mechanical fastening such as bolting. Adhesive bonding does not require notches and loads are distributed over a larger surface than in mechanical joints. Adhesion is attracting interest in many industry fields, nowadays it is used commonly in aerospace, automotive, and electrical industries, civil and medical sectors due to its numerous advantages [2]. Specifically, epoxy adhesives are used to bond metal materials, composites, and concrete structures. In Aerospace industry, adhesive bonding helps to obtain lightweight structures, reduce stress concentration and corrosion. However, adhesives have a few disadvantages related to environmental conditions, but their main disadvantage is their insulating behavior. Thus, in recent years there is a tendency to convert insulating adhesives into electrically and thermally conductive materials without diminishing their initial properties [3].

Recent studies have already shown that the addition of conductive carbon nanoparticles into epoxy adhesives can efficiently improve their mechanical, thermal, and electrical properties. Different types of carbon additives and especially carbon nanotubes and multilayer graphene, have been investigated over the last two decades due to their significant applications [4]-[11]. Carbon nanotubes (CNTs) considered as one-dimensional (1D) tubes, and after their addition in polymers exhibit superb mechanical properties and electrical properties. On the other hand, multilayer graphene, a two-dimensional (2D) allotrope of carbon, possesses excellent mechanical, electrical and thermal properties, when it is used as additive in nano-reinforced polymers. This makes graphene a more promising candidate over the other carbon nanoparticles to improve the thermal conductivity of epoxy adhesives [12].

A significant number of articles are available in literature regarding mechanical, thermal, electrical, and thermoelectrical properties of epoxy polymers and 
adhesives doped with CNTs or GNPs. For example, Moriche, R. et al. [13] noticed that the addition of $8 \%$ wt. and $10 \%$ wt. GNPs into the epoxy adhesives caused a thermal conductivity enhancement of 206 and 306\%, respectively. Han, J.H. et al. [14] proved that the inclusion of $1 \%$ wt. CNTs into an epoxy adhesive improved its electrical conductivity by 8 orders of magnitude. Debelak, B. et al. [15] prepared epoxy polymers reinforced with $20 \% \mathrm{wt}$. GNPs and observed a $2000 \%$ increase in the thermal conductivity, while with the introduction of $8 \% \mathrm{wt}$. GNPs in the reference material noticed a raise of 4 orders of magnitude in electrical conductivity. Han, S. et al. [16] produced nano-reinforced adhesives with $2 \%$ vol. of GNPs and CNTs. He reported 8 and 9 orders of magnitude improvements in electrical conductivity, respectively. Moreover, Tang, L.C. et al. [17] noticed that the electrical conductivity of composites was increased by 7 orders of magnitude when 1\%wt. MWCNTs were embedded in epoxy resin. Khoramishad, H. et al. [18] showed an $23 \%$ increase with the introduction of $0.1 \%$ wt. MWCNTs into an epoxy adhesive. Yu, A. et al. [19] reported that 20\%vol. GNPs embedded in an epoxy matrix, caused a thermal conductivity enhancement of more than 3000\%. Biercuk, M.J. et al. [20] showed that polymers loaded with $1 \%$ wt. unpurified SWCNTs achieved $125 \%$ increase in thermal conductivity at room temperature. Du, F. et al. [21] reported $220 \%$ increase in thermal conductivity of SWCNTs/epoxy composites relative to the reference material. Fu, Y.X. et al. [22] mentioned that a content of $10.10 \% w t$. graphene sheets enhanced by more than 22 times the thermal conductivity of the pure epoxy resin.

Although either CNTs/ or GNPs/polymer composites have been widely investigated, the simultaneous incorporation of CNTs and GNPs into polymers and adhesives is unusual. This hybrid combination is a new research area, where limited effort has been carried out [23]-[29]. The idea of simultaneous integration of two nano-fillers is the production of hybrid nanocomposites, not only by utilizing the advantages of each individual filler, but also for a possible cooperation between them (synergistic effect) [30] [31].

In this work, we study the influence of two types of carbon nanoparticles, MWCNTs and GNPs, on mechanical, thermal, and electrical properties of epoxy adhesives. Composites with individual MWCNTs or GNPs were manufactured, while a hybrid MWCNTs/GNPs filler was used too. The choice of $\%$ weight content of MWCNTs and GNPs based on maximizing the target property of thermal conductivity, as the percolation threshold of electrical conductivity is low, maintaining simultaneously the functionality of the adhesive. So, the main purpose was to develop multifunctional nano-composites increasing their electrical and thermal performance, without diminishing their mechanical properties.

\section{Materials and Methods}

\subsection{Materials}

The 3M Scotch-WeldTM epoxy adhesive $2216 \mathrm{~B} / \mathrm{A}$, used in this study, is a flexi- 
ble, two-part, room temperature curing epoxy with high peel and shear strength supplied by 3M Company (Saint-Paul, Minnesota, USA). The graphene nanoplatelets (GNPs) were provided by XG Sciences. Inc (Lansing, Michigan, USA). GNPs consist of short stacks of graphene sheets having a platelet shape with an average thickness of approximately 15 nanometers and a typical diameter of 5 microns, while their surface area was about 50 to $80 \mathrm{~m}^{2} / \mathrm{g}$. Multi-walled carbon nanotubes (MWCNTs) are tubular structures that produced by catalyzed chemical vapor deposition (CVD) and were supplied by ARKEMA (Colombe, France). Their diameters were $10-15 \mathrm{~nm}$, their typical length was more than $500 \mathrm{~nm}$ long and their surface area was approximately $230 \mathrm{~m}^{2} / \mathrm{g}$. Finally, a unidirectional carbon prepreg (SIGRAPREG CU150-0/NF-E340/38\%) supplied by SGL CARBON (Wiesbaden, Germany), was used for manufacturing single lap joints for shear testing.

\subsection{Preparation of Samples}

The dispersion of nanoparticles in the adhesive material was carried out using three-roll milling technique, which is described analytically by Kostagiannakopoulou, C. et al. [32]. The preparation of nano-reinforced blends took place in a glove box for safety reasons, where the nanoparticles and Part A of the adhesive were mixed by hand stirring for $2 \mathrm{~min}$. Then, the nanomodified mixtures were fed in the calandar machine, as represented in Figure 1, following specific protocol regarding the milling process. In particular, three cycles of milling were repeated for each gap setting during the processing of nano-blends. Finally, the speed of the apron roll was maintained at $270 \mathrm{rpm}$ throughout the duration of milling procedure. After the milling process, part B of the adhesive was added to the produced blend and the final mixture was poured in silicon rubber molds and cured in an autoclave oven, according to manufacturer recommended curing cycle, at $93^{\circ} \mathrm{C}$ for $1 \mathrm{~h}$ and 6 bars pressure. These bulk materials developed for the measurement of thermal and electrical conductivity. Following this process three different nanocomposites resulted: 1) with $8 \%$ wt. GNPs, 2) with $2 \%$ wt. MWCNTs and 3) with the combination of $1 \%$ wt. MWCNTs and $8 \%$ wt. GNPs. Finally, neat epoxy adhesive samples were also produced following the above process to have the reference values in order to investigate the influence of nanoparticles on the material properties.
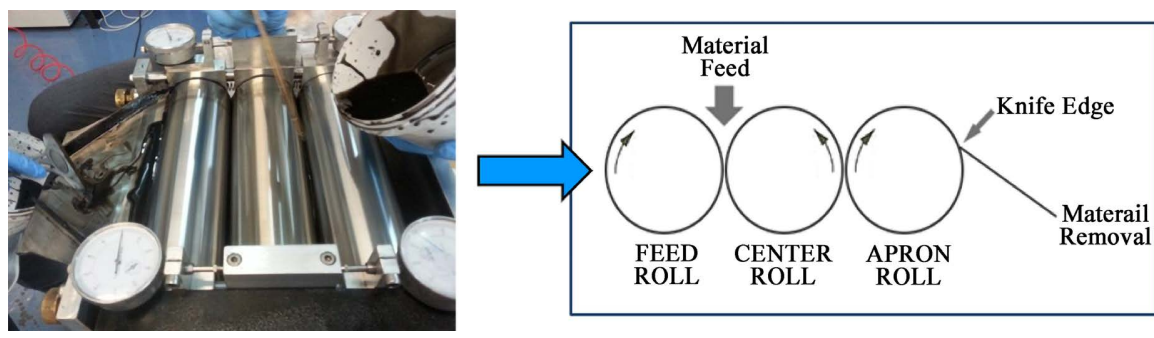

Figure 1. Three-roll mill device and schematic presentation of milling process for the production of nano-reinforced polymers. 
Moreover, for the single lap shear tests, coupons were manufactured according to ASTM D5868-01. Both the adherends were taken from UD ([0] $\left.{ }_{16}\right)$ carbon fiber composite plates, which were cured according to the manufacturer's instructions in an autoclave oven ( 6 bar pressure, 2 hours at $120^{\circ} \mathrm{C}$ ). Coupons with dimensions of $100 \mathrm{~mm}$ length by $25 \mathrm{~mm}$ width were cut from the CFRP plates using a water-cooled diamond coated disc cutter. After cutting, the samples were properly dried. The areas, where the adhesive was to be applied, were prepared by wet abrasion ( $\mathrm{SiC}$ paper, P600) and cleaned thoroughly using acetone. Immediately after preparation, adhesive was applied onto the one of the adherends, in such a way that a $25 \mathrm{~mm}$ by $25 \mathrm{~mm}$ joint to be achieved. Using appropriate shims, the second adherend was placed on top of the first, and alignment was ensured. The system was then placed in a conventional oven for curing as per the adhesive manufacturer's instructions $\left(93^{\circ} \mathrm{C}\right.$ for $\left.1 \mathrm{~h}\right)$. Reference specimens were produced this way, using as-received adhesive, as well as the nano-modified, using the developed formulas containing GNPs, MWCNTs and the hybrid system.

\subsection{Instrumentation and Characterization}

Firstly, for the electrical characterization of the developed materials DC electrical conductivity measurements were performed. A digital multimeter (Keithley 2002) was used for the through thickness measurements of specific electrical resistance of samples (Figure 2(a)). Four specimens were measured for each material type. The dimensions of the measured samples were $(25 \mathrm{~mm} \times 25 \mathrm{~mm} \times 5$ $\mathrm{mm})$.

Then, measurements of thermal conductivity of the developed materials were per-formed by using a thermal conductivity analyzer (TCi Mathis), as depicted in Figure 2(b). TCi Mathis Analyzer measures directly and rapidly the through thickness thermal conductivity of sample at room temperature, providing a detailed overview of its thermal characteristics. Five specimens were measured for each tested material type. The dimensions of the measured samples were $(25 \mathrm{~mm}$ $\times 25 \mathrm{~mm} \times 5 \mathrm{~mm}$ ).

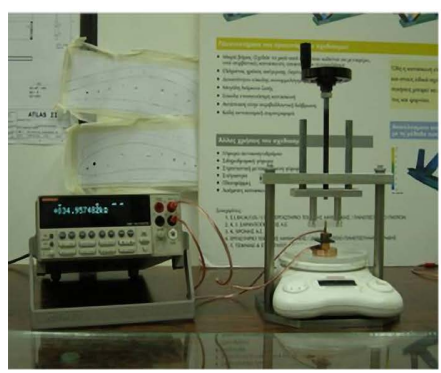

(a)

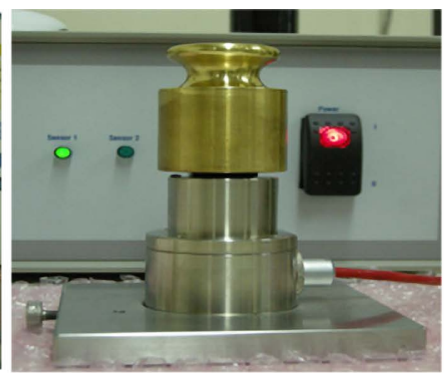

(b)

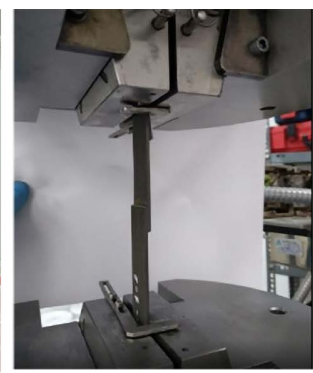

(c)

Figure 2. Three Experimental devices: (a) Digital multimeter (Keithley 2002) for the through thickness measurement of the electrical resistance; (b) TCi Mathis Analyzer for the through thickness measurement of the thermal conductivity; (c) Hydraulic universal testing machine (Instron 8802) for the single lap shear test. 
For the single lap shear tests, a hydraulic universal testing machine (Instron 8802) was used (Figure 2(c)). Single lap shear tests were carried out according to ASTM D 5868-01 standard. The crosshead speed was set at $13 \mathrm{~mm} / \mathrm{min}$, while five specimens were tested for each produced material. Finally, the fracture surfaces of the tested coupons were carefully examined under a LEO SUPRA 35VP Scanning Electron Microscopy (SEM).

\section{Results and Discussion}

\subsection{Electrical Conductivity Measurements}

The measured electrical conductivity of the reference material and the developed formulations are shown in Figure 3. An electrical conductivity of about $10^{-12}$ $\mathrm{S} / \mathrm{m}$ was measured in case of unmodified epoxy adhesive, which is expected due to its typical insulating behavior. The electrical conductivity of the epoxy adhesive is increased by several orders of magnitude, when the conductive nano-fillers are introduced into the reference material. More specifically, the last column of Table 1 reports the increases, in order of magnitude, caused in electrical conductivity of

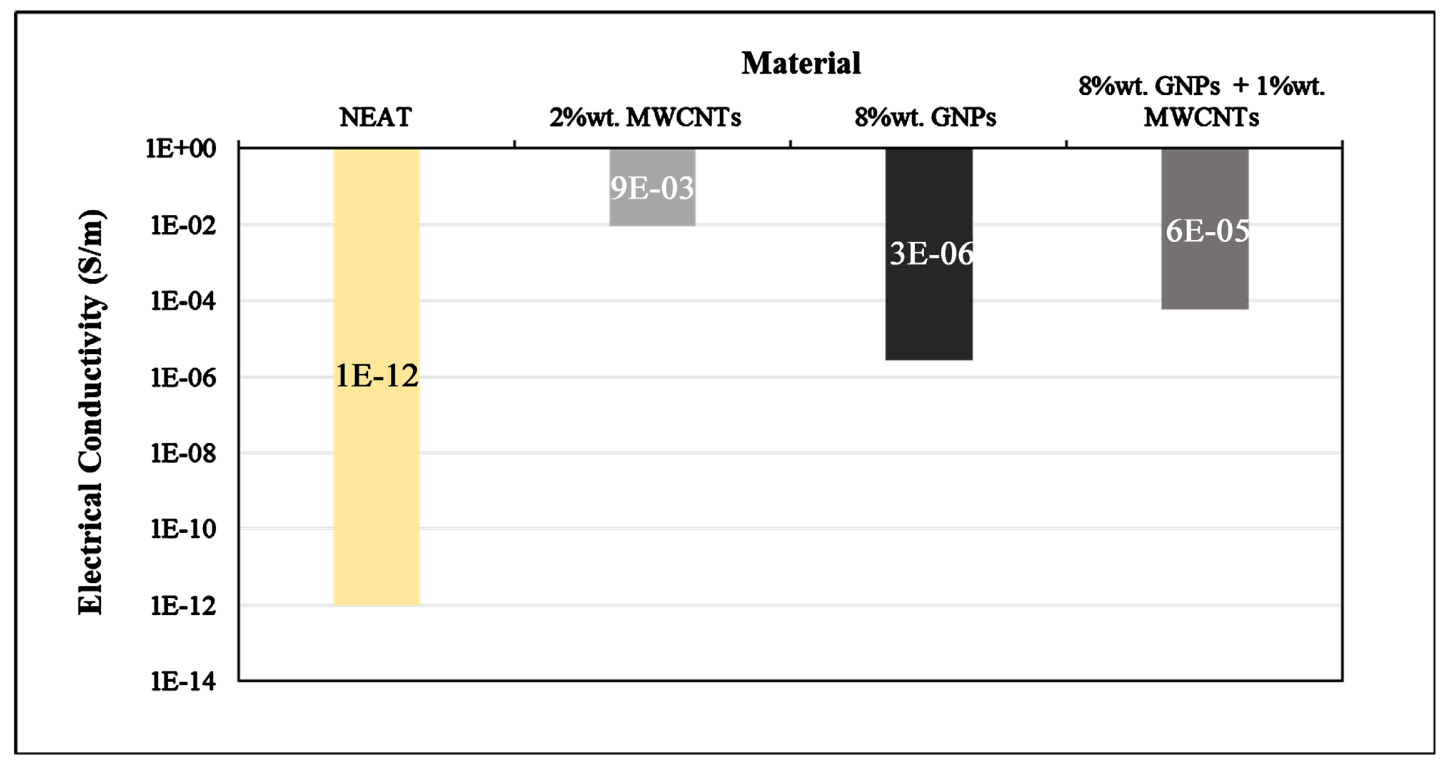

Figure 3. Electrical conductivity of neat and nano-reinforced adhesives. Schematic presentation for $2 \%$ wt. MWCNTs, $8 \%$ wt. GNPs, $8 \% w t$. GNPs + 1\%wt. MWCNTs.

Table 1. DC out of plane electrical conductivity measurements of neat and nano-reinforced adhesives.

\begin{tabular}{cccc}
\hline Material & $\begin{array}{c}\text { Electrical } \\
\text { conductivity }(\mathrm{S} / \mathrm{m})\end{array}$ & $\begin{array}{c}\text { Standard } \\
\text { Deviation }\end{array}$ & $\begin{array}{c}\text { Increase (orders } \\
\text { of magnitude) }\end{array}$ \\
\hline Pure epoxy adhesive & $\sim 1 \mathrm{E}-12$ & - & \\
2\%wt. MWCNTs & $9.45 \mathrm{E}-03$ & $1.67 \mathrm{E}-04$ & 9 \\
$8 \%$ wt. GNPs & $2.78 \mathrm{E}-06$ & $1.41 \mathrm{E}-07$ & 6 \\
$8 \%$ wt. GNPs + 1\%wt. MWCNTs & $5.82 \mathrm{E}-05$ & $8.27 \mathrm{E}-06$ & 7 \\
\hline
\end{tabular}


the adhesive by the addition of carbon nanoparticles. As it can be seen, the highest increase, 9 orders of magnitude, was observed in the case of nano-modified adhesive doped with $2 \%$ wt. MWCNTs. The addition of $8 \%$ wt. GNPs into the epoxy adhesive improved its electrical conductivity by 6 orders of magnitude, while the simultaneous integration of MWCNTs and GNPs did not lead to further improvement of the property.

Considering the results, MWCNTs proved more efficient nano-fillers for the enhancement of the electrical conductivity of adhesives in comparison with GNPs. According to literature, MWCNTs cause significant improvements in electrical conductivity of epoxy resins (polymer and adhesives) converting them from insulators to conductors or semi-contactors by achieving low percolation thresholds [20] [21] [22] [32] [33]. It is well known that one of the main factors that considerably affects the electrical properties of the nano-reinforced materials is the filler geometry, [33]-[39]. The superiority of MWCNTs relative to graphene nano-filler for the improvement of electrical conductivity is due to the $2 \mathrm{D}$ nature of GNPs that may cause greater scattering to the electron transfer compared to the 1D-geometry MWCNTs. The 2D geometry leads to lesser mean free path of electrons into the material [39], and thus to the inability of forming the appropriate conductive channels. So, enhancement of electrical conductivity is limited in the case of the graphene-based materials in relation to MWCNTs.

At this point it is worth mentioning that the hybrid material containing both MWCNTs and GNPs did not cause further improvement in electrical conductivity than the corresponding materials doped with the individual nanoparticles. It is obvious, that the improvement that was achieved in hybrid system was mainly due to the presence of multi-walled carbon nanotubes into the epoxy adhesive. This fact proved that no synergetic effect between the nano-fillers for further increase of electrical properties of the adhesive was observed.

\subsection{Thermal Conductivity Measurements}

Figure 4 depicts thermal conductivity results of base and nano-reinforced adhesives for each filler type. Table 2 also summarizes the resulted average values of thermal conductivity measurements and their standard deviation. Furthermore, Table 2 presents the percentage increase that was achieved by adding carbon nanofillers to the adhesive relative to the base material. It is obvious that the thermal conductivity of adhesive increased with the incorporation of carbon nanofillers. By adding a reinforcement content of $8 \% \mathrm{wt}$. GNPs, the thermal conductivity enhanced by $207 \%$. The hybrid material resulted to an almost similar enhancement and increased the thermal conductivity by $203 \%$, while the addition of MWCNTs caused the lowest improvement of $17 \%$.

As already mentioned, the major enhancement of the thermal conductivity was succeeded by GNPs. According to literature [14]-[22], multilayer graphene is a very promising nanomaterial for the development of thermally conductive polymers for two reasons. Firstly, the 2D geometry of graphene-based materials 


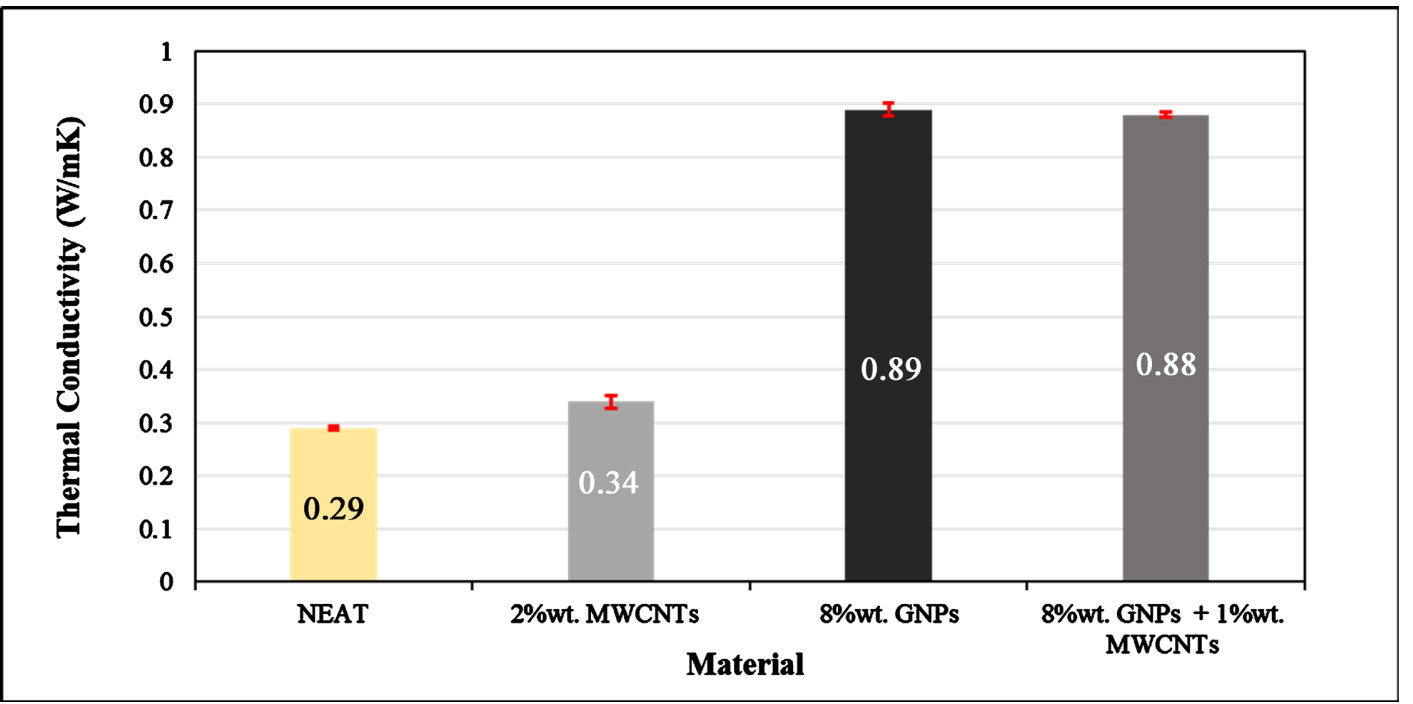

Figure 4. Thermal conductivity of neat and nano-reinforced adhesives. Schematic presentation for $2 \%$ wt. MWCNTs, $8 \%$ wt. GNPs, $8 \%$ wt. GNPs + 1\%wt. MWCNTs.

Table 2. Out of plane thermal conductivity measurements of neat and nano-reinforced adhesives.

\begin{tabular}{cccc}
\hline Material & $\begin{array}{c}\text { Thermal conductivity } \\
(\mathrm{W} / \mathrm{mK})\end{array}$ & $\begin{array}{c}\text { Standard } \\
\text { Deviation }\end{array}$ & Increase (\%) \\
\hline Pure epoxy adhesive & 0.29 & 0.004 & \\
2\%wt. MWCNTs & 0.34 & 0.012 & 17 \\
8\%wt. GNPs & 0.89 & 0.011 & 207 \\
8\%wt. GNPs + 1\%wt. MWCNTs & 0.88 & 0.005 & 203 \\
\hline
\end{tabular}

provides a $2 \mathrm{D}$ path, which leads to a more efficient phonon transmission between adjacent nanoparticles compared to the corresponding 1D path formed by carbon nanotubes [40]. Then, the geometry of GNPs in contrast to MWCNTs allows the development of high content nano-modified mixtures without introducing limitations during the manufacturing process due to the increased viscosity. That is a very important fact, considering that fillers contents higher than $5 \%$ wt. are needed to successfully increase the property of thermal conductivity. At lower concentrations the distance between fillers increases and leads to an increase in the thickness layer of the insulating polymer, forming between them preventing the direct transmission of phonons.

Finally, the hybrid material did not show any further increase in thermal conductivity, which indicates that there was no cooperation between MWCNTs and GNPs to facilitate the phonon transmission inside the material. Obviously, the reported enhancement in the case of hybrid system is only due to the presence of GNPs into the epoxy adhesive.

\subsection{Mechanical Tests}

The single lap shear strength of pure and nano-reinforced epoxy adhesives is 
presented in Figure 5. In this figure and in the Table 3, it is observed that the incorporation of nanofiller into the epoxy adhesive decreased the single lap shear strength of the reference material. The most significant reduction is observed with the addition of $2 \%$ wt. MWCNTs and this was at the level of $74 \%$. The incorporation of GNPs caused a decrease of $17 \%$, while the hybrid system presented the lowest decrease (10\%). The quite high decrease of the single lap shear strength that occurred in nano-reinforced adhesives with MWCNTs resulted due to the high viscosity of the prepared adhesive that introduced difficulties in handling and applying the adhesive material. Obviously, the reduction of $74 \%$ proves that the addition of high contents of MWCNTs into the adhesives carries the risk of losing the adhesive's operational properties.

\subsection{SEM}

In the following figures, SEM micrographs of the fracture surfaces of nanoreinforced polymers are presented. More specifically, representative SEM micrographs of nano-doped materials filled with $2 \%$ wt. MWCNTs, $8 \%$ wt. GNPs and the combination of $1 \%$ wt. MWCNTs \& $8 \%$ wt. GNPs are shown in Figures 6-8, respectively. In Figure 6(a), the dispersion of multi-walled carbon nanotubes

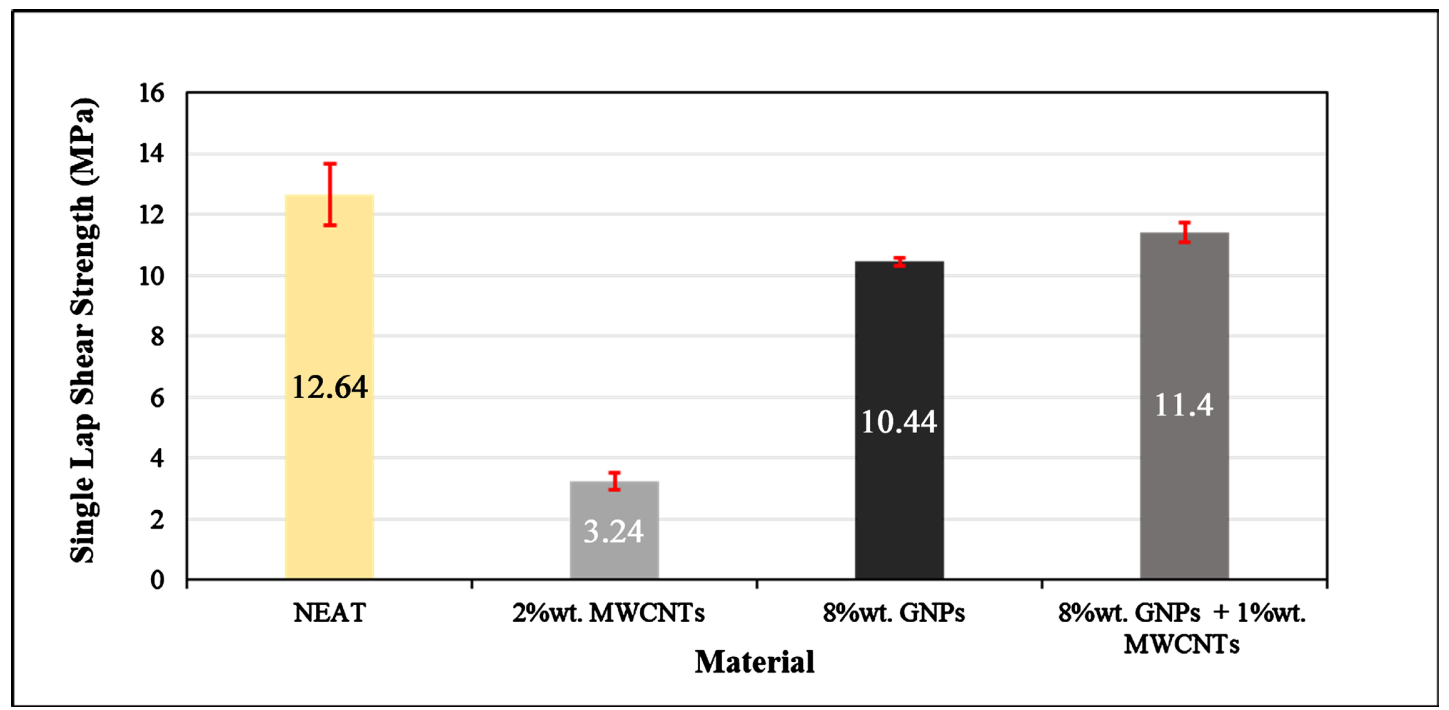

Figure 5. Single lap shear strength of neat and nano-reinforced adhesives. Schematic presentation for $2 \%$ wt. MWCNTs, $8 \%$ wt. GNPs, $8 \%$ wt. GNPs + 1\%wt. MWCNTs.

Table 3. Single lap shear strength values of neat and nano-reinforced adhesives.

\begin{tabular}{cccc}
\hline Material & $\begin{array}{c}\text { Lap Shear } \\
\text { Strength }(\mathrm{MPa})\end{array}$ & $\begin{array}{c}\text { Standard } \\
\text { Deviation }\end{array}$ & Increase (\%) \\
\hline Pure epoxy adhesive & 0.29 & 1.007 & \\
2\%wt. MWCNTs & 0.34 & 0.270 & -74 \\
8\%wt. GNPs & 0.89 & 0.114 & -17 \\
8\%wt. GNPs + 1\%wt. MWCNTs & 0.88 & 0.330 & -10 \\
\hline
\end{tabular}




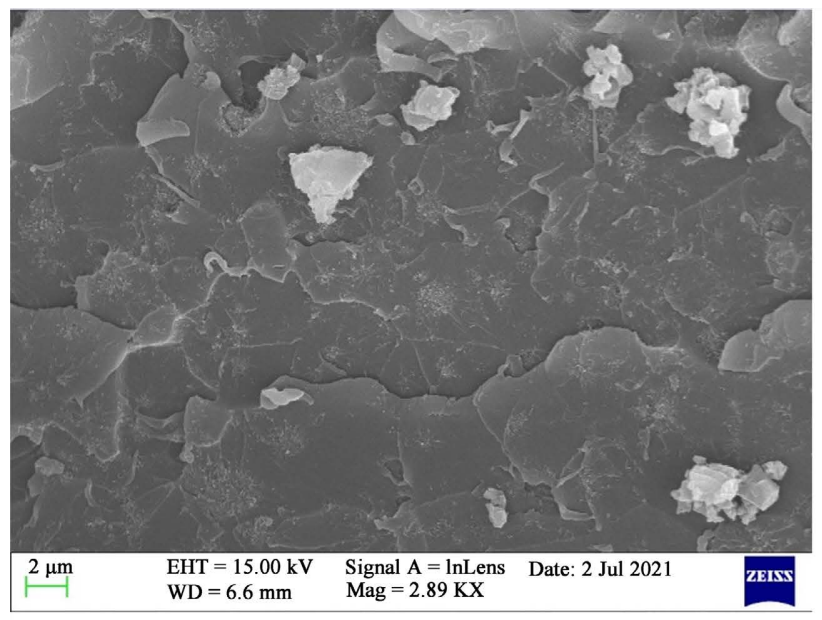

(a)

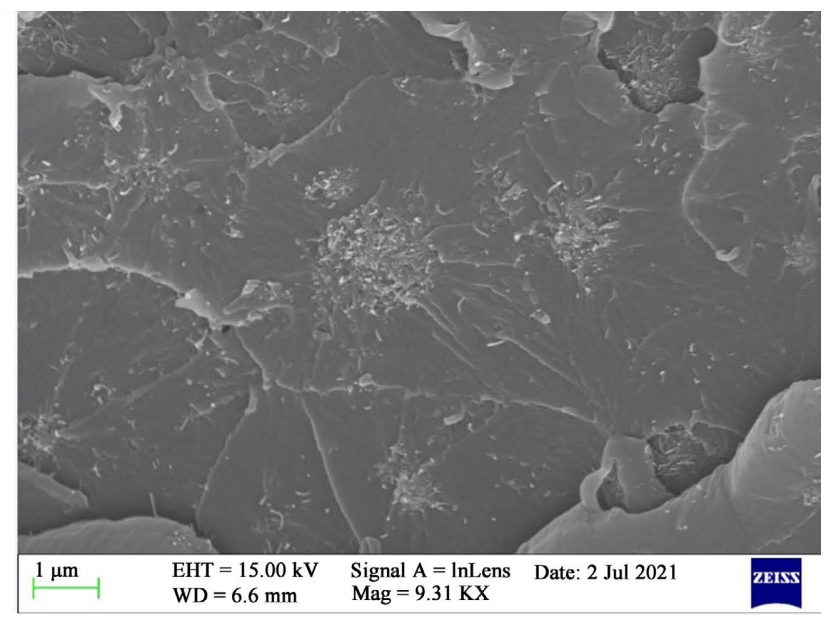

(b)

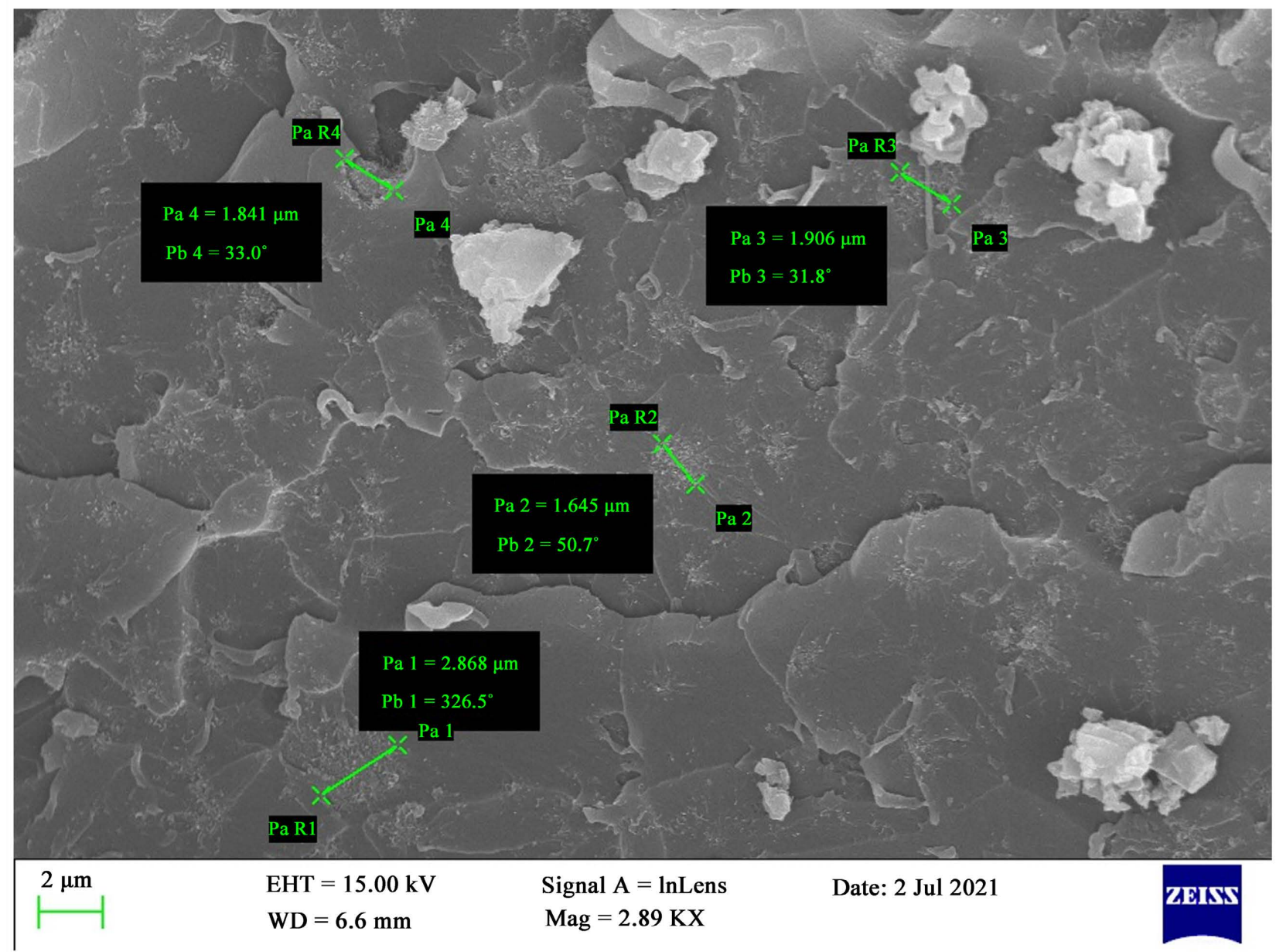

(c)

Figure 6. SEM images of (a) dispersed MWCNTs in matrix; (b) agglomerates between MWCNTs; (c) size of agglomerates, (2\%wt. MWCNTs nano-reinforced epoxy adhesive).

into the epoxy adhesive is shown. It is obvious that there is insufficient homogeneity in the dispersion of MWCNTs into the epoxy adhesive. The presence of agglomerates is evident in Figure 6(b) at higher magnification. Measurements of 
the size of representative agglomerates are presented in Figure 6(c), and the average size of the agglomerates is $2.065 \mu \mathrm{m}$. This intense agglomeration into the epoxy adhesive in case of MWCNTs possibly led to high viscosity, which in turns caused difficulties in handling of the material. Also, the presence of agglomeration is responsible for the strong decrease (74\%) of the single lap shear strength after the integration of MWCNTs into the epoxy adhesive.

Next, it can be seen in Figure 7(a) that the introduction of GNPs into the epoxy adhesive showed greater homogeneity in comparison with that of MWCNTs. More specifically, in Figure 7(b) the high content of GNPs into the epoxy adhesive, in combination with their 2D geometry, led to the successful formation of appropriate conductive paths (green arrows) for the phonon transmission, which is responsible for the increase of the thermal conductivity of the reference material.

In this study, the simultaneous introduction of GNPs and MWCNTs into the epoxy adhesive did not report much different values in thermal and electrical conductivity than the corresponding values resulted from the addition of the individual nanoparticles. The combined use of MWCNTs and GNPs increases slightly ( 1 order of magnitude) the electrical conductivity compared to the pure GNPs, while reduces marginally the thermal conductivity compared again to the pure GNPs. However, the combined use of the specific carbon based nanofillers keeps very high values of single lap shear strength values. This fact proved that although there is no synergy between MWCNTs and GNPs on the thermal and electrical conductivity, the addition of both carbon nanoparticles presents a combined effect. Based on these data, the hybrid GNPs/MWCNTs material presented a better combination of properties than the neat composites, leading to the successful development of multifunctional adhesives by utilizing filler's advantages for the improvement of each property.

Until now, the relatively published results have been controversial. Li, Y. et al.

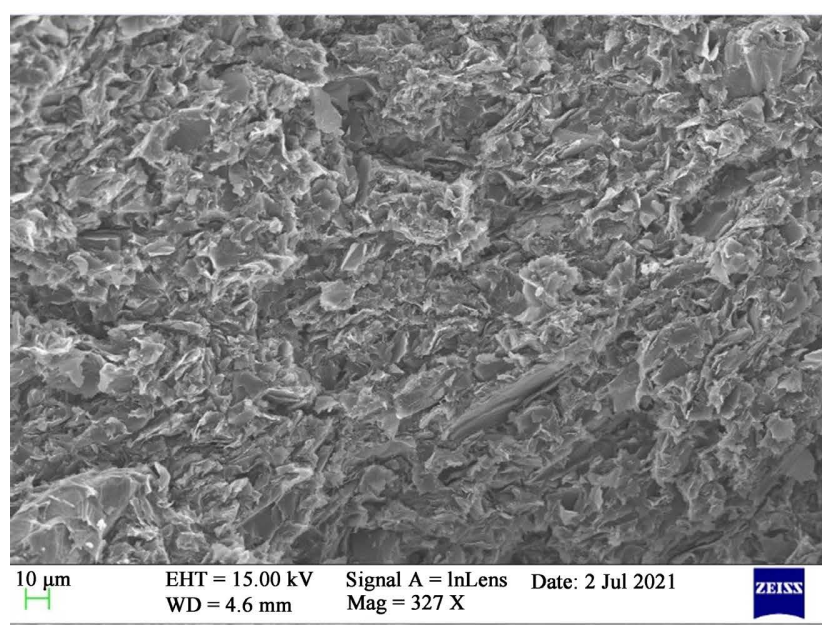

(a)

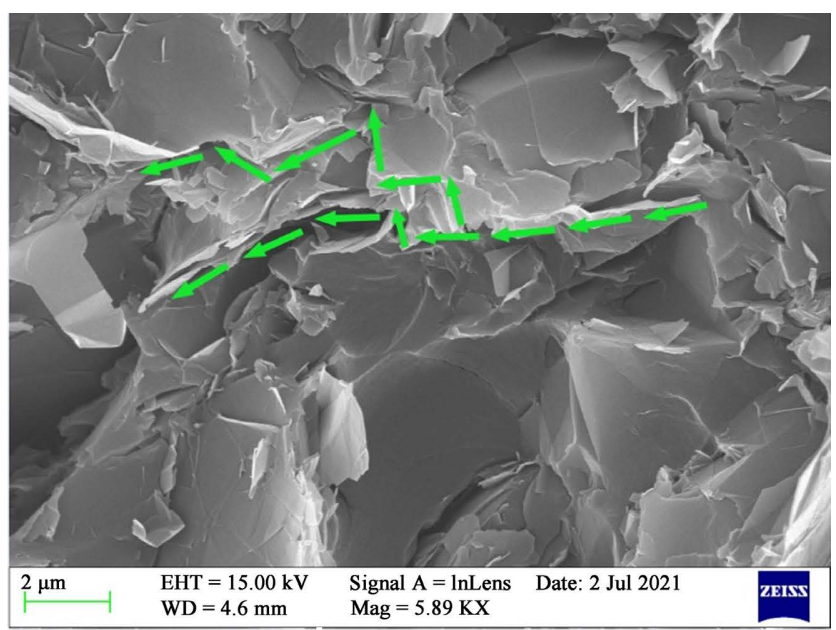

(b)

Figure 7. SEM images of (a) dispersed GNPs in matrix; (b) the conductive path that was created from adjacent GNPs for the phonon transmission, (8\%wt. GNPs nano-reinforced epoxy adhesive). 
[41] published a remarkable synergistic effect between CNTs and GO sheets, which improved the mechanical properties of the epoxy. Yue, L. et al. [42] reported that a hybrid nanofiller of CNTs and GNPs at a mass ratio of 8:2 synergistically contributed to increased flexural properties and a reduction of the electrical percolation threshold in epoxy composites. It was reported that the hybrid nanofiller demonstrated a reduced percolation threshold (pc) of $0.62 \%$ wt. in contrast to the CNT and GNP single-filled composites, which exhibited pc values of $0.84 \%$ wt. and $0.88 \%$ wt., respectively. This was attributed to the more efficient formation of conductive pathways between the carbon nanoparticles. In contrast, Im, H. et al. [43] did not find a synergistic effect on the storage modulus of epoxies reinforced with GO nanoplatelets and MWCNTs. However, the same author showed a synergistic effect for the thermal conductivity of the studied composites. Han, S. and coworkers et al. [23] reported a synergistic effect of graphene and carbon nanotubes on lap shear strength and electrical conductivity of epoxy adhesives. Kopsidas, S. et al. [25] measured a synergetic increase in both electrical conductivity and fracture toughness of epoxy polymers doped simultaneously with GNPs and CNTs at a mass ratio of 9:1. However, no significant differences were observed in the tensile properties and the glass transition temperature for the carbon-modified epoxies.

In the following SEM micrographs (Figures 8(a)-(d)), it can be seen the simultaneous dispersion of two fillers into the epoxy adhesive. In Figure 8(b), the squares indicate the representative GNPs, while the corresponding MWCNTs were circled. Figures 8 (b)-(d) present the simultaneous integration of fillers into the epoxy adhesive at different magnifications. There is no clear cooperation between them for the creation of conductive channels and paths, which are needed for the improvement of electrical and thermal conductivity of the adhesives, respectively. This is probably attributed to the weak interfacial adhesion between the matrix and the carbon nanofillers. The presence of strong interfacial adhesion is necessary for effective reinforcement as it allows stress transfer from the high modulus filler to the low modulus polymer matrix. However, this can only be achieved when the two parts are chemically compatible. For this reason, efforts have been focused on functionalizing the carbon nanoparticles [28], without implying that there will be the desired results [27].

\section{Conclusions}

In the present study, graphene nanoplatelets (GNPs) and multi-walled carbon nanotubes (MWCNTs) enhanced epoxy adhesives successfully. With the addition of nanoparticles inside the epoxy adhesive, an improvement in thermal and electrical conductivity was observed.

The $8 \%$ wt. multilayer graphene reinforcement presented the highest enhancement in thermal conductivity, giving an increase of $207 \%$ compared to unreinforced epoxy adhesive. However, it is observed that the introduction of GNPs inside the epoxy adhesive led to degradation of mechanical properties. 


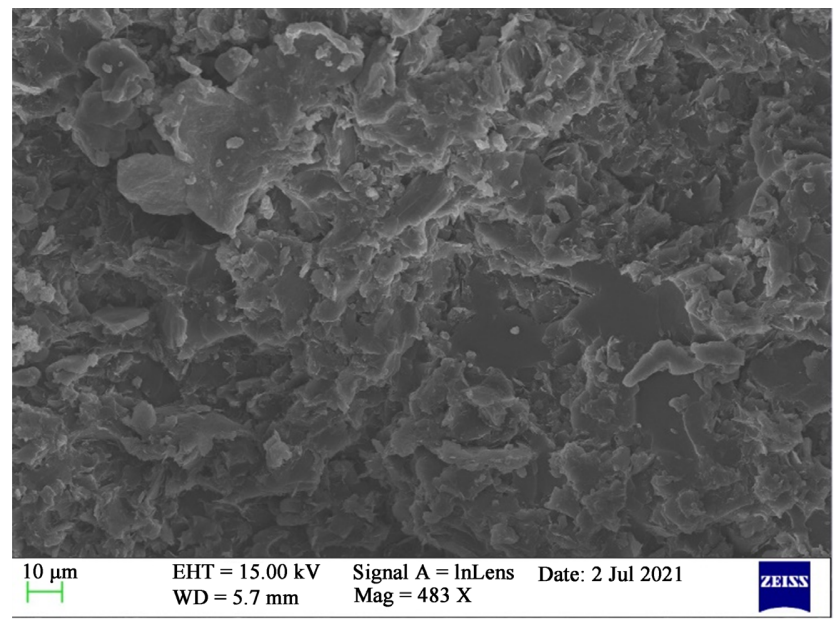

(a)

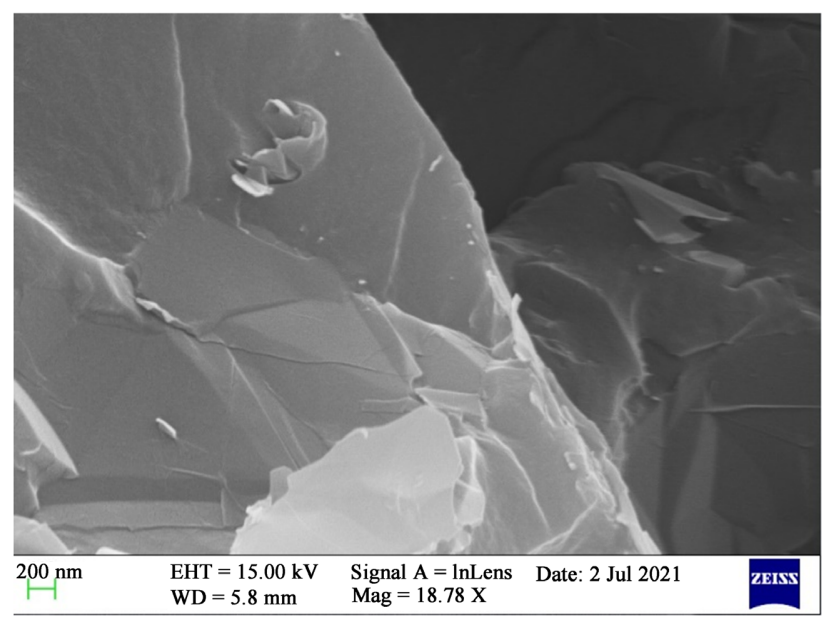

(c)

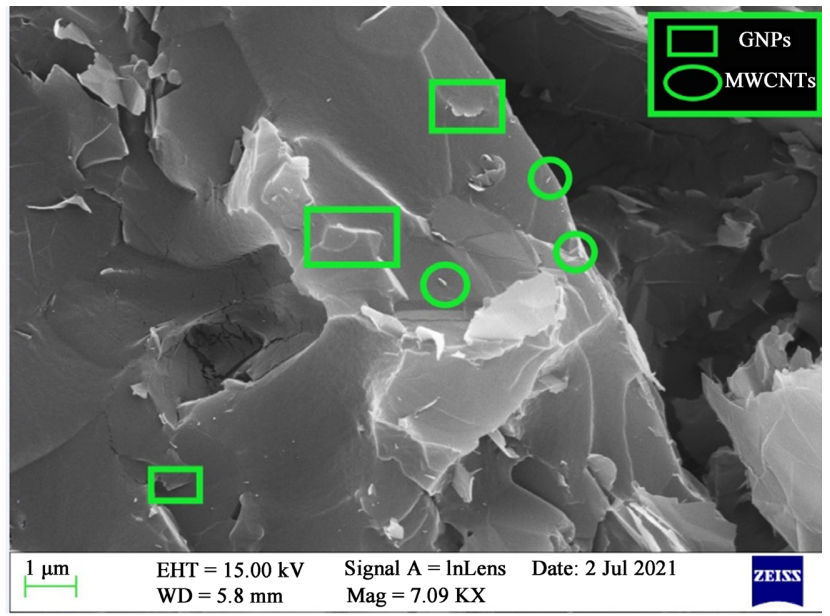

(b)

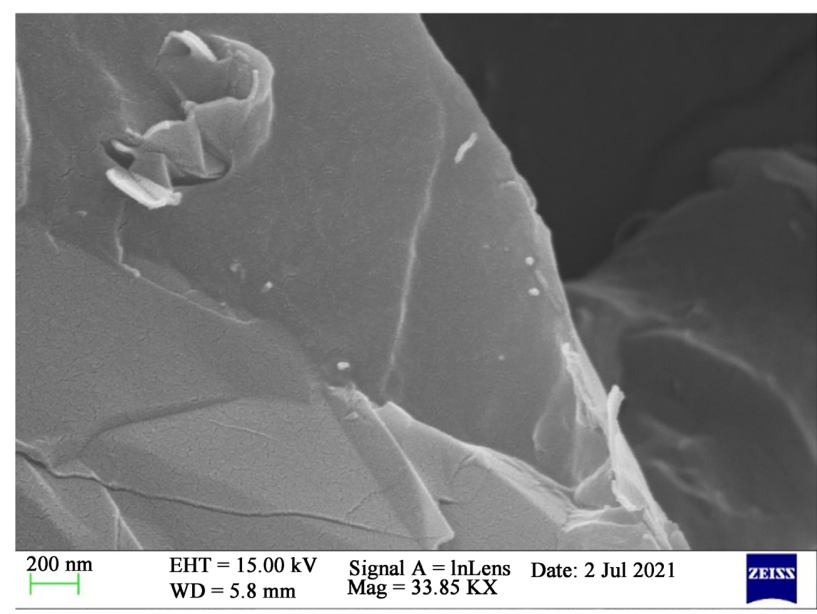

(d)

Figure 8. SEM images of ((a), (c), (d)) the simultaneous dispersion of GNPs and MWCNTs (hybrid material) into the epoxy adhesive at different magnifications; (b) the representative GNPs with green square and the MWCNTs with green circle.

Additionally, the addition of conductive nanoparticles converted the adhesive from an insulator to a conductive material. The material that caused the largest increase ( 9 orders of magnitude) was the carbon nanotubes (MWCNTs) in a content of $2 \%$ wt.. However, this addition of MWCNTs significantly degraded the mechanical properties of the material, as a result the epoxy adhesive lost its adhesive capacity.

The need to create a multi-functional material led to the development of a new hybrid material (8\%wt. GNPs and 1\%wt. MWCNTs). It was observed that the hybrid system successfully contributed to the development of a multi-functional epoxy adhesive, which improved thermal and electrical properties without significantly degrading its mechanical properties. The combination of GNPs and MWCNTs improved the electrical conductivity of the epoxy adhesive 7 orders of magnitude and the thermal conductivity with an increase of $203 \%$.

\section{Authors' Contributions}

Conceptualization, C.K. and G.S.; methodology, C.K. and G.S.; formal analysis, 
M.G. and C.V.; writing-original draft preparation, K.Z. and C.V.; writing-review and editing, T.L. and V.K.; supervision, V.K.; project administration, S.T. All authors have read and agreed to the published version of the manuscript.

\section{Funding}

This research was funded by the Operational Programme "Competitiveness, Entrepreneurship and Innovation" (NSRF 2014-2020).

\section{Acknowledgements}

We acknowledge support of this work by the project "INVALOR: Research Infrastructure for Waste Valorization and Sustainable Management" (MIS 5002495) which is implemented under the Action "Reinforcement of the Research and Innovation Infrastructure", funded by the Operational Programme "Competitiveness, Entrepreneurship and Innovation" (NSRF 2014-2020) and co-financed by Greece and the European Union (European Regional Development Fund).

\section{Conflicts of Interest}

The authors declare no conflicts of interest regarding the publication of this paper.

\section{References}

[1] Sadigh, M.A.S. and Marami, G. (2018) Enhancing Fatigue Life in Adhesively Bonded Joints Using Reduced Graphene Oxide Additive: Experimental and Numerical Evaluation. International Journal of Adhesion and Adhesives, 84, 283-290. https://doi.org/10.1016/j.ijadhadh.2018.04.001

[2] Kim, C.H. and Choi, J.H. (2017) Effects of Dispersion Methods and Surface Treatment of Carbon Nano-Tubes on Defect Detectability and Static Strengths of Adhesive Joints. Composite Structures, 176, 684-691. https://doi.org/10.1016/j.compstruct.2017.05.077

[3] Jia, Z., Feng, X. and Zou, Y. (2018) An Investigation on Mode II Fracture Toughness Enhancement of Epoxy Adhesive Using Graphene Nanoplatelets. Composites Part B: Engineering, 155, 452-456. https://doi.org/10.1016/j.compositesb.2018.09.094

[4] Gude, M.R., Prolongo, S.G. and Ureña, A. (2015) Toughening Effect of Carbon Nanotubes and Carbon Nanofibres in Epoxy Adhesives for Joining Carbon Fibre Laminates. International Journal of Adhesion and Adhesives, 62, 139-145. https://doi.org/10.1016/j.ijadhadh.2015.07.011

[5] Amirbeygi, H., Khosravi, H. and Tohidlou, E. (2019) Reinforcing Effects of Aminosilane-Functionalized Graphene on the Tribological and Mechanical Behaviors of Epoxy Nanocomposites. Journal of Applied Polymer Science, 136, Article No. 47410. https://doi.org/10.1002/app.47410

[6] Mostovoy, A., Yakovlev, A., Tseluikin, V. and Lopukhova, M. (2020) Epoxy Nanocomposites Reinforced with Functionalized Carbon Nanotubes. Polymers, 12, Article No. 1816. https://doi.org/10.3390/polym12081816

[7] Mostovoy, A.S. and Yakovlev, A.V. (2019) Reinforcement of Epoxy Composites with Graphite-Graphene Structures. Scientific Reports, 9, Article No. 16246. https://doi.org/10.1038/s41598-019-52751-Z 
[8] Shen, J., Huang, W., Wu, L., Hu, Y. and Ye, M. (2007) The Reinforcement Role of Different Amino-Functionalized Multi-Walled Carbon Nanotubes in Epoxy Nanocomposites. Composites Science and Technology, 67, 3041-3050. https://doi.org/10.1016/j.compscitech.2007.04.025

[9] Tsantzalis, S., Karapappas, P., Vavouliotis, A., Tsotra, P., Paipetis, A., Kostopoulos, V. and Friedrich, K. (2007) Enhancement of the Mechanical Performance of an Epoxy Resin and Fiber Reinforced Epoxy Resin Composites by the Introduction of CNF and PZT Particles at the Microscale. Composites Part A: Applied Science and Manufacturing, 38, 1076-1081. https://doi.org/10.1016/j.compositesa.2006.04.015

[10] Karapappas, P., Vavouliotis, A., Tsotra, P., Kostopoulos, V. and Paipetis, A. (2009) Enhanced Fracture Properties of Carbon Reinforced Composites by the Addition of Multi-Wall Carbon Nanotubes. Journal of Composite Materials, 43, 977-985. https://doi.org/10.1177/0021998308097735

[11] Zafeiropoulou, K., Kostagiannakopoulou, C., Sotiriadis, G. and Kostopoulos, V. (2020) A Preliminary Study of the Influence of Graphene Nanoplatelet Specific Surface Area on the Interlaminar Fracture Properties of Carbon Fiber/Epoxy Composites. Polymers, 12, Article No. 3060. https://doi.org/10.3390/polym12123060

[12] Kumar, R., Mohanty, S. and Nayak, S.K. (2020) Thermal Conductive Epoxy Adhesive Composites Filled with Carbon-Based Particulate Fillers: A Comparative Study. Journal of Adhesion Science and Technology, 34, 807-827. https://doi.org/10.1080/01694243.2019.1646062

[13] Moriche, R., Prolongo, S.G., Sánchez, M., Jiménez-Suárez, A., Chamizo, F.J. and Ureña, A. (2016) Thermal Conductivity and Lap Shear Strength of GNP/Epoxy Nanocomposites Adhesives. International Journal of Adhesion and Adhesives, 68, 407410. https://doi.org/10.1016/j.ijadhadh.2015.12.012

[14] Han, J.H., Zhang, H., Chen, M.J., Wang, D., Liu, Q., Wu, Q.L. and Zhang, Z. (2015) The Combination of Carbon Nanotube Buckypaper and Insulating Adhesive for Lightning Strike Protection of the Carbon Fiber/Epoxy Laminates. Carbon, 94, 101113. https://doi.org/10.1016/j.carbon.2015.06.026

[15] Debelak, B. and Lafdi, K. (2007) Use of Exfoliated Graphite Filler to Enhance Polymer Physical Properties. Carbon, 45, 1727-1734.

https://doi.org/10.1016/j.carbon.2007.05.010

[16] Han, S., Meng, Q., Araby, S., Liu, T. and Demiral, M. (2019) Mechanical and Electrical Properties of Graphene and Carbon Nanotube Reinforced Epoxy Adhesives: Experimental and Numerical Analysis. Composites Part A: Applied Science and Manufacturing, 120, 116-126. https://doi.org/10.1016/j.compositesa.2019.02.027

[17] Tang, L.C., Wan, Y.J., Peng, K., Pei, Y.B., Wu, L.B., Chen, L.M. and Lai, G.Q. (2013) Fracture Toughness and Electrical Conductivity of Epoxy Composites Filled with Carbon Nanotubes and Spherical Particles. Composites Part A: Applied Science and Manufacturing, 45, 95-101. https://doi.org/10.1016/j.compositesa.2012.09.012

[18] Khoramishad, H., Ashofteh, R.S., Mobasheri, M. and Berto, F. (2018) Temperature Dependence of the Shear Strength in Adhesively Bonded Joints Reinforced with Multi-Walled Carbon Nanotubes. Engineering Fracture Mechanics, 199, 179-187. https://doi.org/10.1016/j.engfracmech.2018.05.032

[19] Yu, A., Ramesh, P., Itkis, M.E., Bekyarova, E. and Haddon, R.C. (2007) Graphite Nanoplatelet-Epoxy Composite Thermal Interface Materials. The Journal of Physical Chemistry C, 111, 7565-7569. https://doi.org/10.1021/jp071761s

[20] Biercuk, M.J., Llaguno, M.C., Radosavljevic, M., Hyun, J.K., Johnson, A.T. and Fischer, J.E. (2002) Carbon Nanotube Composites for Thermal Management. Applied Physics Letters, 80, 2767-2769. https://doi.org/10.1063/1.1469696 
[21] Du, F., Guthy, C., Kashiwagi, T., Fischer, J.E. and Winey, K.I. (2006) An Infiltration Method for Preparing Single-Wall Nanotube/Epoxy Composites with Improved Thermal Conductivity. Journal of Polymer Science Part B: Polymer Physics, 44, 15131519. https://doi.org/10.1002/polb.20801

[22] Fu, Y.X., He, Z.X., Mo, D.C. and Lu, S.S. (2014) Thermal Conductivity Enhancement of Epoxy Adhesive Using Graphene Sheets as Additives. International Journal of Thermal Sciences, 86, 276-283. https://doi.org/10.1016/j.ijthermalsci.2014.07.011

[23] Han, S., Meng, Q., Pan, X., Liu, T., Zhang, S., Wang, Y. and Araby, S. (2019) Synergistic Effect of Graphene and Carbon Nanotube on Lap Shear Strength and Electrical Conductivity of Epoxy Adhesives. Journal of Applied Polymer Science, 136, Article ID: 48056. https://doi.org/10.1002/app.48056

[24] Jyoti, J. and Singh, B.P. (2021) A Review on 3D Graphene-Carbon Nanotube Hybrid Polymer Nanocomposites. Journal of Materials Science, 56, 17411-17456. https://doi.org/10.1007/s10853-021-06370-7

[25] Kopsidas, S. and Olowojoba, G.B. (2021) Multifunctional Epoxy Composites Modified with a Graphene Nanoplatelet/Carbon Nanotube Hybrid. Journal of Applied Polymer Science, 138, Article ID: 50890. https://doi.org/10.1002/app.50890

[26] Kumar, A., Sharma, K. and Dixit, A.R. (2021) A Review on the Mechanical Properties of Polymer Composites Reinforced by Carbon Nanotubes and Graphene. Carbon Letters, 31, 149-165. https://doi.org/10.1007/s42823-020-00161-x

[27] Prolongo, S.G., Moriche, R., Ureña, A., Flórez, S., Gaztelumendi, I., Arribas, C. and Prolongo, M.G. (2018) Carbon Nanotubes and Graphene into Thermosetting Composites: Synergy and Combined Effect. Journal of Applied Polymer Science, 135, Article ID: 46475. https://doi.org/10.1002/app.46475

[28] Wang, B., Dou, S., Li, W. and Gao, Y. (2020) Multifunctional Reduced Graphene Oxide/Carbon Nanotubes/Epoxy Resin Nanocomposites Based on Carbon Nanohybrid Preform. Soft Materials, 18, 89-100. https://doi.org/10.1080/1539445X.2019.1688833

[29] Wegrzyn, M., Ortega, A., Benedito, A. and Gimenez, E. (2015) Thermal and Electrical Conductivity of Melt Mixed Polycarbonate Hybrid Composites Co-Filled with Multi-Walled Carbon Nanotubes and Graphene Nanoplatelets. Journal of Applied Polymer Science, 132, Article ID: 42536. https://doi.org/10.1002/app.42536

[30] Zhu, C., Li, S., Cong, X. and Liu, X. (2020) Mechanical Properties of Bio-Based Epoxy Composites Reinforced with Hybrid-Interlayer Ramie and Recycled Carbon Fibres. Open Journal of Composite Materials, 10, 118-133. https://doi.org/10.4236/ojcm.2020.104009

[31] Divya, G.S. and Suresha, B. (2018) Role of Metallic Nanofillers on Mechanical and Tribological Behaviour of Carbon Fabric Reinforced Epoxy Composites. Materials Sciences and Applications, 9, 740-750. https://doi.org/10.4236/msa.2018.99054

[32] Kostagiannakopoulou, C., Loutas, T.H., Sotiriadis, G., Markou, A. and Kostopoulos, V. (2015) On the Interlaminar Fracture Toughness of Carbon Fiber Composites Enhanced with Graphene Nano-Species. Composites Science and Technology, 118, 217-225. https://doi.org/10.1016/j.compscitech.2015.08.017

[33] Vavouliotis, A., Fiamegou, E., Karapappas, P., Psarras, G.C. and Kostopoulos, V. (2010) DC and AC Conductivity in Epoxy Resin/Multiwall Carbon Nanotubes Percolative System. Polymer Composites, 31, 1874-1880. https://doi.org/10.1002/pc.20981

[34] Martin, C.A., Sandler, J.K.W., Shaffer, M.S.P., Schwarz, M.K., Bauhofer, W., Schulte, K. and Windle, A.H. (2004) Formation of Percolating Networks in Multi-Wall Car- 
bon-Nanotube-Epoxy Composites. Composites Science and Technology, 64, 23092316. https://doi.org/10.1016/i.compscitech.2004.01.025

[35] Sandler, J., Shaffer, M.S.P., Prasse, T., Bauhofer, W., Schulte, K. and Windle, A.H. (1999) Development of a Dispersion Process for Carbon Nanotubes in an Epoxy Matrix and the Resulting Electrical Properties. Polymer, 40, 5967-5971. https://doi.org/10.1016/S0032-3861(99)00166-4

[36] Thostenson, E.T. and Chou, T.W. (2006) Processing-Structure-Multi-Functional Property Relationship in Carbon Nanotube/Epoxy Composites. Carbon, 44, 3022-3029. https://doi.org/10.1016/j.carbon.2006.05.014

[37] Sandler, J., Kirk, J.E., Kinloch, I.A., Shaffer, M.S.P. and Windle, A.H. (2003) Ultra-Low Electrical Percolation Threshold in Carbon-Nanotube-Epoxy Composites. Polymer, 44, 5893-5899. https://doi.org/10.1016/S0032-3861(03)00539-1

[38] Chen, G., Weng, W., Wu, D. and Wu, C. (2003) PMMA/Graphite Nanosheets Composite and Its Conducting Properties. European Polymer Journal, 39, 2329-2335. https://doi.org/10.1016/j.eurpolymj.2003.08.005

[39] Kumar, S., Sun, L.L., Caceres, S., Li, B., Wood, W., Perugini, A. and Zhong, W.H. (2010) Dynamic Synergy of Graphitic Nanoplatelets and Multi-Walled Carbon Nanotubes in Polyetherimide Nanocomposites. Nanotechnology, 21, Article ID: 105702. https://doi.org/10.1088/0957-4484/21/10/105702

[40] Yu, A., Ramesh, P., Sun, X., Bekyarova, E., Itkis, M.E. and Haddon, R.C. (2008) Enhanced Thermal Conductivity in a Hybrid Graphite Nanoplatelet-Carbon Nanotube Filler for Epoxy Composites. Advanced Materials, 20, 4740-4744. https://doi.org/10.1002/adma.200800401

[41] Li, Y., Umer, R., Isakovic, A., Samad, Y.A., Zheng, L. and Liao, K. (2013) Synergistic Toughening of Epoxy with Carbon Nanotubes and Graphene Oxide for Improved Long-Term Performance. RSC advances, 3, 8849-8856. https://doi.org/10.1039/c3ra22300k

[42] Yue, L., Pircheraghi, G., Monemian, S.A. and Manas-Zloczower, I. (2014) Epoxy Composites with Carbon Nanotubes and Graphene Nanoplatelets-Dispersion and Synergy Effects. Carbon, 78, 268-278. https://doi.org/10.1016/j.carbon.2014.07.003

[43] Im, H. and Kim, J. (2012) Thermal Conductivity of a Graphene Oxide-Carbon Nanotube Hybrid/Epoxy Composite. Carbon, 50, 5429-5440.

https://doi.org/10.1016/j.carbon.2012.07.029 